The Council of the Zoological Society of London has therefore decided to make financial provision for a scheme to produce an entirely new "Nomenclator", in which an attempt will be made to include every generic name used in zoology from 1758 up to and including 1935. It is estimated that this will involve about 190,000 names, of which about 100,000 relate to insects. The names from 1758 to 1879 will be given their original references, these being taken, so far as those up to 1850 are concerned, from Sherborn. From 1880 onwards, the "Nomenclator" will take the form of an index to the "Zoological Record" itself. The class of animal concerned, or in the case of insects, the order, will also be given.

A very intensive search is being made of the literature to discover names that have been omitted from existing records, and this has already resulted in the discovery of some seven hundred in insects alone, chiefly among publications that appeared between 1900 and 1920. It is hoped also to enlist the aid of all systematic zoologists throughout the world in making the work as complete as possible, and a circular asking for their help is being sent out. In the course of this, they are asked to send details of any generic names, with their original references, to Dr. S. A. Neave, of the Imperial Institute of Entomology, 41 Queen's Gate, London, S.W.7, who is supervising the undertaking on behalf of the Zoological Society of London, and will also have the assistance, in particular groups, of experts at the British Museum (Natural History).

It is hoped that the work may be completed for publication about the end of 1937, and that it will be found possible to issue it at a moderate price.

\title{
Solid Carbon Dioxide
}

IT is just a hundred years ago since carbon 1 dioxide was first solidified by Thilorier. Most chemists are familiar with carbon dioxide 'snow', which has long found use in the laboratory as a convenient means of producing temperatures down to about $-80^{\circ} \mathrm{C}$. The comparatively small quantities required for such purposes were obtained by the simple but wasteful method of allowing liquid carbon dioxide from a cylinder to expand through a valve into a collecting bag; in these circumstances less than 30 per cent of the weight of the liquid used is obtained in the form of 'snow'.

Until about ten years ago, the solid was only used as a laboratory freezing agent, and also in small quantities medically as a cauterising agent. For the latter purpose the 'snow' was usually pressed into a solid pencil in a mould, making it more convenient to handle, and, owing to the reduced surface exposed, less rapid in evaporation.

The commercial development of the manufacture of solid carbon dioxide became a possibility only when refrigeration began to play a large part in the organisation of food supply. A great impetus was given by the rapid growth of the ice-cream industry in the United States, where the annual production (under the familiar name of 'dry ice') rose from a few tons in 1925 to approximately 27,000 tons in 1933. In Great Britain, production on a large scale commenced several years later, but it is estimated that the output in 1934 reached 10,000 tons, and demand for the product continues to expand.

In Great Britain, the gas for the production of solid carbon dioxide is chiefly derived as a byproduct from industrial processes, such as the manufacture of synthetic ammonia, and in the production of alcohol. Purification in greater or less degree depending on the source of gas is required in all cases, including the removal of odoriferous compounds and of inert non-condensable gases which, under certain conditions, and if present in sufficient quantity, would render the liquefaction of the carbon dioxide difficult or even impossible. Following liquefaction of the gas, solidification may be brought about by various processes. These, while relatively simple, are very interesting from the physico-chemical point of view ; and their development on the most economic lines has been the result of much research on the phase rule and thermodynamic aspect of the system. The process most commonly adopted is to allow the liquid to expand in suitable chambers with the formation of gas and 'snow', the latter being pressed into blocks of convenient size and shape, and the gas being returned for recompression. In another process, the liquid carbon dioxide is expanded in chambers at a pressure just below that corresponding to the triple point, and solid blocks are obtained without the use of a press, while according to a third process the liquid is frozen in moulds by the rapid evaporation of liquid ammonia. As might be expected, the several processes differ considerably in thermodynamic efficiency, although this is not reflected appreciably in the cost of production, power costs being only a small fraction of the whole.

Solid carbon dioxide in its commercial form is available in blocks of cylindrical or rectangular section, weighing approximately $25 \mathrm{lb}$. These blocks have the appearance of highly compressed snow and may be cut without difficulty by means 
of an ordinary saw. The temperature of the solid under a pressure of one atmosphere of carbon dioxide is $-78.9^{\circ} \mathrm{C}$., but when exposed to the atmosphere is somewhat lower owing to the reduction of partial pressure of carbon dioxide near the surface of the block. On account of the low temperature, gloves should always be worn when handling the solid. In a still atmosphere, a block of the solid evaporates more slowly than might be expected, mainly on account of the low conductivity of the enveloping film of gaseous carbon dioxide and of the high latent heat of sublimation of the solid (137 cal./gm. at $-78.9^{\circ}$ C.). Thus a $25 \mathrm{lb}$. block requires about 24 hours to evaporate completely.

The most careful measures have to be taken to prevent needless waste by evaporation both in storage and transport, and to this end heavily insulated storage bins have been designed in which the evaporation loss has been reduced to 0.5 per cent a day, while the evaporation in large railway transport containers is of the order of only 2 per cent a day. Research into the most suitable types of container and insulating material has led to the development of a range of packages suitable for the transport of solid carbon dioxide, which enables this product to be sent from the producing centre to depots in all parts of the country, and thence to the user, with a very small total loss. Although the solid can be stored for very long periods without serious loss, it has been found that a limit is set by the slow growth of the crystals, which tends to produce disintegration.

As might be expected, the principal uses for solid carbon dioxide are in connexion with refrigeration. Its dryness, high latent heat and high density $(1 \cdot 4)$ render it attractive in many cases where the cost of removing heat units is not the only consideration. As already stated, the icecream industry was the first to adopt this refrigerant on a large scale in place of ice and salt mixtures, and the requirements of this industry continue to expand.

A considerable field exists for solid carbon dioxide in connexion with the transport of perishables, such as meat, fish, fruit and flowers, where controlled temperature conditions are required. As a result of the work which has recently been carried out under the auspices of the Department of Scientific and Industrial Research at Cambridge and at the Torry Research Station, and by other investigators, it is now known that carbon dioxide inhibits, in a marked degree, the growth of many of the bacteria and moulds which are largely responsible for the deterioration of meat and fish, so that the value of solid carbon dioxide as a refrigerant and preservative is further enhanced on this account. In preserving flowers, however, the effect is one of arrested metabolism due to the low temperature and the presence of carbon dioxide.

It may be remarked that, although the successful utilisation of solid carbon dioxide as a refrigerant presents no serious technical difficulties, care must be taken in the design of equipment such as icecream conservators, refrigerated transport containers and the like, if this refrigerant is to be used successfully and economically.

Except where the low temperature of solid carbon dioxide is specially required, means must be taken to reduce the heat flow to the refrigerant, and this can be done conveniently by interposing thermal insulation between the refrigerant and the cooled chamber. A number of other methods employing a secondary liquid are available.

Reference has already been made in Nature (Oct. 6, 1934, p. 529) to the use of solid carbon dioxide in the assembly of machine components by means of shrink fits. The effect of the low temperature in contracting metal parts is best attained by immersing the parts in a suitable low freezing point liquid containing solid carbon dioxide. In this way rapid and uniform cooling results. The advantages of this method of shrink fitting are that it enables small components, such as cylinder liners, sleeves and valve seats to be readily inserted into housings without the use of a press, thereby obviating the possibility of distortion, and that the structure of heat-treated parts is not disturbed as might be the case with hot shrinking. Solid carbon dioxide is already being used in Great Britain in the production of automobile and aero engines, locomotives and machine tools, and this application is likely to expand considerably as it becomes more widely appreciated.

The use of solid carbon dioxide as a convenient means of obtaining a supply of the liquid or gas was first realised by Elworthy who, in a patent obtained in 1898, discussed the economic advantage to be gained from handling carbon dioxide in the solid form instead of as a liquid in heavy steel cylinders. It is only recently, however, that these advantages have been secured as a result of the development of solid carbon dioxide for refriger. ating purposes, and the design of suitable containers and other apparatus. Pressure vessels ('liquefiers') are now available which enable the solid to be readily converted into liquid or gaseous form, and the use of solid carbon dioxide for purposes other than refrigeration is rapidly expanding. Foremost amongst these uses must be placed the carbonation and mechanical handling of beverages for which, it is needless to say, only solid carbon dioxide of the highest purity can be employed. For example, in 'Drikold', 
manufactured by Imperial Chemical Industries,Ltd., organic esters and sulphur compounds are reduced to less than one part per million, and any oil which may be carried over from the compressors is carefully removed in order to obtain a sufficiently pure product. The solid is also finding increasing use as a source of carbon dioxide for the production of salicylic acid and other chemicals.
Passing reference only has been made to some of the principal uses of solid carbon dioxide. Certain other applications are still in the development stage, while others are constantly being discovered. The development of the industry has been very rapid and constitutes one of the most remarkable modern examples of the application of scientific methods to industrial requirements.

\section{Obituary}

\section{Prof. Arthur Thomson}

$\mathrm{O}^{\mathrm{N}}$ his retirement in 1933, Prof. Arthur Thomson, whose death on February 7 will be widely regretted, had completed a somewhat unusual record of academic service. He was born on March 21, 1858, and for forty-eight years he represented human anatomy at the University of Oxford, first as University lecturer in human anatomy and afterwards as Dr. Lee's professor of anatomy. After serving an apprenticeship in the famous school of anatomy at Edinburgh under Sir William Turner, Thomson went to Oxford in 1885. Unlike many of his later contemporaries, he did not enjoy the advantage of stepping into a department already equipped for teaching and research. On the contrary, the task fell to him of building up a new department from its very foundations. It will readily be appreciated that Thomson's energies were fully employed for a number of years in developing the teaching side of his department to a level appropriate to the medical faculty of the University of Oxford, a task which was rendered very laborious at first by the criticism and opposition of some members of the University who were less ready to appreciate the importance of catering for an extensive and detailed medical curriculum.

Arthur Thomson's own contributions to scientific literature can be divided quite sharply into separate categories. Of these, his papers dealing with the racial variations of the skeleton are the most noteworthy. In this work he was clearly influenced by his late teacher, Sir William Turner, who had stimulated considerable interest in racial anatomy by his studies of the human skeleton in the Challenger Reports. Thomson's work on this subject was characterised by the fact that he constantly sought to explain by reference to habits of life and environmental influences the osteological variations which were being at that time recorded by anatomists. He was not content simply with measurements and with the construction of indices, and he was evidently reluctant to accept metrical variations of the skeleton as necessarily of real morphological significance in the assessment of racial affinities. In 1889 he showed the importance of considering posture as a factor in the determination of the proportions and contour of the lower limb skeleton and directed attention to the 'squatting facets' on the tibia and talus. In the same year he published an anthropometrical study of the Veddahs of Ceylon. His interest in craniology led him to investigate the significance of cranial indices which were then assuming such importance in the eyes of the anthropologist. By ingenious models he sought to show that the proportions of the calvarium must be directly influenced by brain volume and by the action of the temporal muscles. These observations were published in the Journal of the Anthropological Institute in 1903, and his conclusions, which were admittedly tentative, have in some part been substantiated by statistical study on a larger scale.

In 1913, Thomson made a valuable communication on the correlation of isotherms with variations in the nasal index. Ten years later, this observation was submitted to statistical analysis by him in collaboration with Dr. Buxton, with the noteworthy conclusion that a platyrrhine nasal index is associated with a hot moist climate and a leptorrhine index with a cold dry climate. Other studies by Thomson in this line include a comprehensive study with D. Randall-MacIver of Egyptian crania, published in 1905 by the Clarendon Press under the title of "The Ancient Races of the Thebaid", and a paper on the genial tubercles of the mandible in 1915. At Oxford, Thomson will be particularly remembered with gratitude for the part he played in instituting and organising the regular course of study for the University diploma in anthropology, a course which has met with increasing success since its initiation in 1907.

Thomson was a close personal friend of the late R. W. Doyne, who founded the Oxford Ophthalmological Congress, and undoubtedly it was this friendship which led him to make special studies of the anatomy of the eye. This resulted in the publication of two papers on the filtration angle of the eye in 1910 and 1911, and in a brochure on the anatomy of the human eye together with an atlas of stereoscopic photographs of dissections of the eye.

Thomson's last work was concerned with the microscopic structure of the human Graafian follicle and the maturation of the human ovum. These provided the subjects for two papers in the Journal of Anatomy in 1919.

Apart from his work at the University of Oxford, Thomson occupied the position of professor of anatomy at the Royal Academy, to which he was elected in 1900. In this sphere he was able to give full expression to his own artistic propensities, and he left an appropriate memorial of his contribution to art in his book "Anatomy for Art Students" which has passed through a number of editions. 